\title{
Reutilization of Leftovers from Agro-Industries for Textile Applications: A Mini Report
}

\author{
Binoj JS*, Bhanu Palampalle, Manikandan N and Krishnamachary PC \\ Department of Mechanical Engineering, Sree Vidyanikethan Engineering College (Autonomous), Tirupati - 517102, Andhra Pradesh, India \\ *Corresponding author: Binoj JS, Department of Mechanical Engineering, Sree Vidyanikethan Engineering College (Autonomous), Tirupati - 517102, \\ Andhra Pradesh, India
}

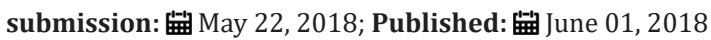

Keywords: Discarded; Fruit fibers; Agro-industries; Non-toxic; Textile industry

\section{Opinion}

In the present scenario, environmental anxieties and human heath are the two major factors concentrated in many engineering sectors. Man-made vitreous fibers and its usage in many diverse applications are exhibiting better properties on one face, whereas on the other turn it sparks a lot of harmful situations to the atmosphere and people involved. Moreover, nowadays due to enactment of governmental laws, extraction of green raw materials and development of green products for many applications without disturbing the nature are under progress. Plant based fibers used in the textile engineering are being extracted by the harvesting of flora, which in turn increases the deforestation and also diminishes the safety factor of the earth in near future. Meanwhile, the animal based fibers being used in the textile engineering are extracted after the slaughter of faunas, which again leads to destruction of living beings in huge amount. In addition the existing fibers used in textile engineering are of very high cost and not economically viable. However, huge amount of agro wastes with potential fiber contents are being discarded from many industries are to be explored to meet the increasing demand for natural raw materials as well as it can solve the above critical issues in the collection of raw material for textile processing industries.

The properties of a natural fiber depend on plant type, its age, climatic condition in which they grow and even the extraction procedures. Discarded agro wastes from industries after crushing of its economical values are having certain advantages such as low cost, non-toxic, light weight, readily available, easy to extract and harmless which makes it a better source material for textile processing industries. The present report briefly describes the feasibility investigation done on industrially discarded fruit fibers which was collected, extracted and characterized for its viability as an alternate for synthetic, plant and animal based fibers used in the textile fields. The experimentally tested values of the discarded fiber ensure its potentiality as a suitable alternative for harmful man-made fibers and other type of fibers used in textile engineering applications. The plant/tree discarded from the agro-industries after yielding and their botanical names are given in Table 1.

Table 1: Botanical name of discarded fruit fibers from agro industries.

\begin{tabular}{|c|c|c|}
\hline Sl. No & Fiber & Botanical Name \\
\hline 1 & Coconut & Cocus nucifera $L$. \\
\hline 2 & Oil palm & Elaeis guineensis $L$. \\
\hline 3 & Palmyrah & Borassus flabellifer $L$. \\
\hline 4 & Kapok & Ceiba pentandra $L$. \\
\hline 5 & Sponge groud & Luffa cylindrica $L$. \\
\hline 6 & Areca palm & Areca catechu $L$. \\
\hline 7 & Tamarind tree & Tamarindus indica $L$. \\
\hline
\end{tabular}

Many researchers have investigated on the above listed fruit fibers and found to have controlled potential properties for replacing the synthetic fibers. Moreover, the reported works has emphasized on the physical, chemical, morphological, thermal and water absorption properties of discarded fruit fibers. Considering the carcinogenic and environmental problems associated with the synthetic fibers, the discarded fruit fibers are a promising source with the desired specific properties to manufacture useful products with sustainability in any applications. Utilization of these discarded fruit fibers will reduce the deforestation, economic issues and the environmental problems, since they are recycled from the waste and converted into useful products. Hence, based on the literature discarded fruit fibers from agro-industries having remarkable properties can be utilized as a raw material for the textile engineering applications instead of using the injurious synthetic fibers or destructed trees or slaughtered animals. 
Creative Commons Attribution 4.0 International License

For possible submissions Click Here
TTEFT

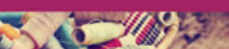

Submit Article
Trends in Textile Engineering \& Fashion Technology

\section{Benefits of Publishing with us}

- High-level peer review and editorial services

- Freely accessible online immediately upon publication

- Authors retain the copyright to their work

- Licensing it under a Creative Commons license

- Visibility through different online platforms 